(D-MA), Charles Grassley (R-IA), Howard Metzenbaum (D-OH), and Herbert Kohl (D-WI) made a joint floor statement at the time that the Senate passed H.R. 4412 to emphasize their legislative intent. They asserted that "the effect of the Salinger and New Era decisions has been profound, resulting in chilling uncertainty and serious apprehension in the publishing community regarding fair use of unpublished material." Their statement observed that these two cases had "threatened to establish a virtual per se rule against the fair use of any unpub- lished materials, such as letters and diaries." Thus these Senators concluded that "it is no exaggeration to say that if the trend were to continue, it could severely damage the ability of journalists and scholars to use unpublished primary materials. This would be a crippling blow to accurate scholarship and reporting." The floor statement made clear that the purpose of H.R. 4412 is to "undo the harm caused by the overly restrictive standards adopted in Salinger and the New Era, and to clearly and indisputably reject the view that the unpublished nature of the work triggers a virtual per se ruling against a finding of fair use." The senators specifically noted that H.R. 4412 was necessary to address the limitations of the recent Wright v. Warner Books which "did not explicitly disavow the narrow formulation of the fair use doctrine espoused in Salinger and New Era." With passage of this legislation, the courts will be instructed to make a carefully reasoned and complete consideration of each of the fair use factors set forth in Section 107 of the Copyright Act.

\title{
Changes in the General Social Survey (GSS) in 1994
}

\author{
Tom W. Smith, Director, General Social Survey, \\ National Opinion Research Center (NORC)
}

\section{Redesign of 1994 GSS}

In 1994 two major innovations will be introduced to the GSS. First, the traditional core will be substantially reduced to allow for the creation of mini-modules (i.e., blocks of about 15 minutes devoted to some combination of small to medium size supplements). The mini-modules space will give us greater flexibility to incorporate innovations and to include important items proposed by the social science community.

Second, a new biennial, splitsample design will be initiated. The 3,000-case sample will consist of two parallel sub-samples of 1,500 cases each. As illustrated in Figure 1, the two sub-samples will both contain the identical core. The A sample will also contain a standard, topical module, the mini-modules, and an ISSP module (on women, work, and the family). The B sample will have a second topical module, minimodules, and an ISSP module (on the environment). In effect, one can think of the A sample as representing a traditional GSS for 1994 and the B sample as representing a traditional GSS for 1995. Rather than being fielded separately in two different years, they are fielded together.
While we will generally field separate topical, mini-, and ISSP modules on the A and B samples, we have the option of including some items on both samples if a larger sample size is needed. This would most likely be utilized in the case of the mini-modules.

In 1996 and in subsequent even numbered years the same design described for 1994 would be repeated.

\section{Cuts in Content of GSS Core}

In order to create the minimodules section (see above), the replicating core must be reduced from about 60 minutes to about $45 \mathrm{~min}$ utes. This will mean that many traditional GSS time series will be eliminated. The list of possible deletions compiled by the GSS Board of Overseers and PIs (James A. Davis and Tom W. Smith) is enclosed. Approximately $75 \%$ of the items on this list will have to be deleted from the 1994 GSS.

We urge users who have opinions about the proposed deletions to contact us. If you wish to retain items that appear on the list of possible cuts, you should send us supporting arguments about why the items should be kept. These should refer to such aspects as their theoretical importance, contributions to social science knowledge, usage, trends, connection to other GSS items, etc. Similarly, if you wish to delete items not included on the list, you should present arguments as to why these items should be deleted. All suggestions should reach the GSS no later than March 15, 1993. These comments will be assessed and in light of them the Board and PIs will make final decisions on content in spring 1993.

\section{Additions to the 1994 GSS}

\section{Mini-Modules}

The reduction of the replicating core has opened up space for the addition of new items. We anticipate up to 30 minutes of time to be available on the 1994 GSS (i.e., 15 minutes on each of the two subsamples of 1,500). Reflecting the idea that this space is available to cover a diverse selection of topics ranging from single items to multi-item scales and batteries (as opposed to the topical module that usually focuses on one topic, this space is referred to 


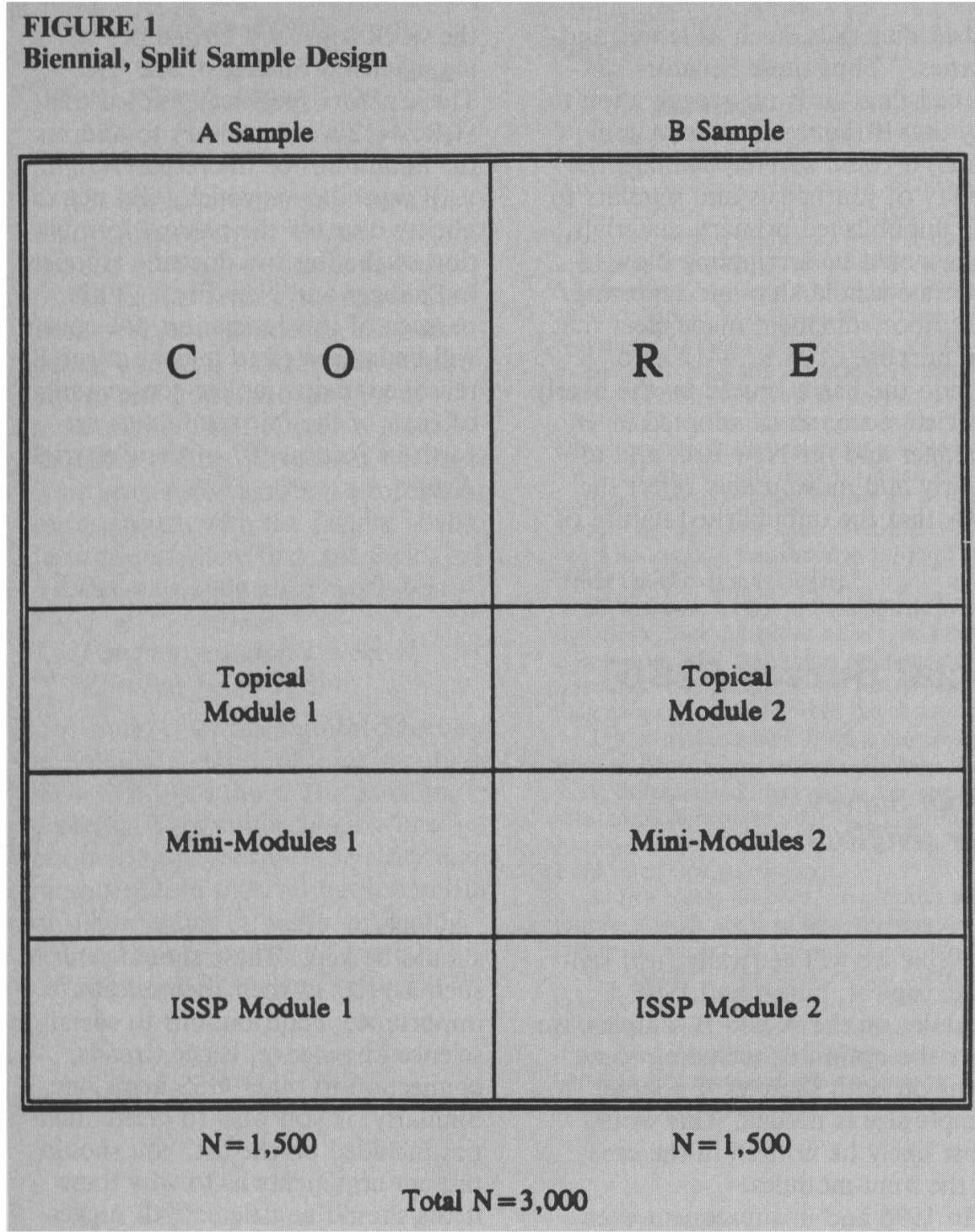

as the mini-modules.

NSF has supplied partial funding for items in the mini-modules. That is, NSF funding covers the cost of most, but not all, of the space in the mini-modules. There is additional space available, but additional funding is needed to fill this space. Thus, proposals that have additional funding or have applied for such will be eligible for this additional space. When submitting proposals for the inclusion of items in the minimodules, researchers should indicate whether they (a) might be able to supply additional funding or (b) will rely on the existing NSF funding to the GSS. Since we anticipate more competition for the "free" minimodule space than for the space depending on additional funding, the chances of having a proposal accepted for the "free" mini-module space might be substantially less than the acceptance probability of proposals that have additional funding.

Researchers who have ideas about items that should be included in the mini-modules should send proposals to the GSS. The proposals should include (a) the items to be added; (b) their theoretical purpose and importance; (c) a review of past usage; (d) any technical information on reliability, validity, and marginals; and (e) the relevance of these items to other variables on the GSS. Proposals should be from 1-5 pages in length. They must be received by March 15, 1993, to be considered for the 1994 GSS. Proposals will be evaluated by the GSS PIs and Board of Overseers, and decisions will be made at the spring 1993 board meeting.

\section{Topical Modules}

As in the past the GSS also encourages the submission of ideas for topical modules (i.e., 15 minutes devoted to one subject). Since the topical modules are major components of the GSS, their development takes considerable time and is handled by subcommittees appointed by the Board of Overseers. The drafting committee elaborates, implements, and eventually pretests proposed topical modules. Ideas for modules for both 1994 and 1996 should be submitted to the GSS as soon as possible.

Please send all comments and proposals to GSS/Board of Overseers, NORC, 1155 East 60th Street, Chicago, IL 60637. For questions contact Tom W. Smith, (312) 753-7877, EMAIL: NNRTWS1 @UCHIMVS1; or Andrea Tyree, (516) 632-7755, EMAIL: ATYREE@SBCCVM.

\section{List of Possible Deletions from GSS Core}

This list organizes items according to topical headings in alphabetical order. The list includes the number of items in each topic, their mnemonic names, and the wording of the items. For some items only partial wordings are given.

\section{Abortion (1)}

Please tell me whether or not you think it should be possible for a pregnant woman to obtain a legal abortion if . . . (G) The woman wants it for any reason? [ABANY]

\section{AIDS (19)}

How many people have you known personally, either living or dead, who came down with the disease called AIDS? [AIDSKNOW] Describe your relationship with that person. [AIDSWHO] Is person living or dead? [AIDSDEAD] Male or female? [AIDSSEX] Age? [AIDSAGE] Race? [AIDSRACE] State/region?

\section{[AIDSREG]}

Same questions for person 2: [AIDSWHO2, AIDSDED2, AIDSSEX2, AIDSAGE2, AIDSRAC2, AIDSREG2]

Same questions for person 3: [AIDSWHO3, AIDSDED3, AIDSSEX3, AIDSAGE3, AIDSRAC3, AIDSREG3]

\section{Anomia (3)}

Agree/disagree with the following 
statements. . . In spite of what some people say the lot of the average man is getting worse, not better. [ANOMIA5] It's hardly fair to bring a child into the world with the way things look for the future. [ANOMIA6] Most public officials are not really interested in the problems of the average man. [ANOMIA7]

\section{Children (2)}

Do you expect to have any (more) children? [CHLDMORE] How many? [CHLDNUM]

\section{Drinking (2)}

Do you ever have occasion to use any alcoholic beverages such as liquor, wine, or beer, or are you a total abstainer? [DRINK] Do you sometimes drink more than you think you should? [DRUNK]

\section{Family of Origin (2)}

Did your mother work as long as a year after you were born and before you started first grade? [MAWKBORN] Thinking about the time when you were 16 years old, compared with American families in general then, would you say your family income was-far below average, below average, average, above average, or far above average? [INCOM16]

\section{International (10)}

Do you think our government should continue to belong to the United Nations or should we pull out of it now? [USUN] Do you think it will be best for the future of this country if we take an active part in world affairs, or if we stay out of world affairs? [USINTL] Do you expect the United States to fight in another world war within the next 10 years? [USWARY] Which of these statements comes closest to how you feel about Communism as a form of government? [COMMUN]

Scale: Like/Dislike countries . . . Canada, China, Russia, Japan, Egypt, Israel [CANADA, CHINA, RUSSIA, JAPAN, EGYPT, ISRAEL]

\section{Job Values (5)}

What do you prefer most in a job? Next most? Third? Fourth? Choices: High income? [JOBINC] No danger of being fired? [JOBSEC) Short working hours, lots of free time? [JOBHOUR] Chances for advancement? [JOBPROMO] Work important and gives a feeling of accomplishment? [JOBMEANS]

\section{Marriage (1)}

How old were you when you first married? [AGEWED]

\section{Media Use (1)}

On the average day, about how many hours do you personally watch television?

\section{[TVHOURS]}

\section{Membership (17)}

Could you tell me whether or not you are a member of each type [of group]? Fraternal groups? [MEMFRAT] Service clubs? [MEMSERV] Veterans' groups? [MEMVET] Political clubs? [MEMPOLIT] Labor unions? [MEMUNION] Sports groups? [MEMSPORT] Youth groups? [MEMYOUTH] School service groups? [MEMSCHL] Hobby or garden clubs? [MEMHOBBY] School fraternities or sororities? [MEMGREEK] Nationality groups? [MEMNAT] Farm organizations? [MEMFARM] Literary, art, discussion or study groups? [MEMLIT] Professional or academic societies? [MEMPROF]

Church-affiliated groups? [MEMCHURH] Any other groups? [MEMOTHER] Total number of memberships [MEMNUM]

\section{Paranormal (2)}

How often have you had any of the following experiences? Felt as though you were really in touch with someone who had died? [SPIRITS] Felt as though you were very close to a powerful, spiritual force that seemed to lift you out of yourself? [GRACE]

\section{Pornography (4)}

I'm going to read some opinions about the effects of looking at or reading sexual/pornographic materials. Do/don't have effect? Sexual materials provide information about sex. [PORNINF] Sexual materials lead to breakdown of morals. [PORNMORL] Sexual materials lead people to commit rape. [PORNRAPE] Sexual materials provide an outlet for bottled-up impulses. [PORNOUT]

\section{Race Relations (5)}

Are there any black families living close to you? [RACCLOS] How many blocks (or miles) away do they live? [RACDIS] Do you think this neighborhood will become black in the next few years, or will it remain integrated? [RACINTEG] Do blacks/whites attend the church that you, yourself, attend most often or not? [RACCHURH] If you and your friends belonged to a social club that would not let blacks/whites join, would you try to change the rules so that blacks/whites could join? [RACCHNG]

\section{Religion (3)}

Where would you place your image of the world on the scale for ... "The world is basically filled with evil and sin" to "There is much goodness in the world which hints at God's goodness"'? [WORLD1] "Human nature is basically good" to "Human nature is fundamentally perverse and corrupt"? [WORLD4] How close do you feel to God most of the time? Extremely close . . . not close at all? [NEARGOD]

\section{Religious Values (4)}

Where would you place your image of God on the scale for ... Mother ... Father [MAPA] Master . . . Spouse [MASTERSP] Judge . . . Lover [JUDGELUV] Friend . . . King [FRNDKING]

\section{Satisfaction (5)}

How much satisfaction do you get from .... The city or place you live in? [SATCITY] Your non-working activities -hobbies and so on? [SATHOBBY] Your family life? [SATFAM] Your friendships? [SATFRND] Your health and physical condition? [SATHEALT]

\section{Smoking (3)}

Do you smoke? [SMOKE] Have you ever tried to give up smoking? [QUITSMK] Have you ever smoked regularly? [EVSMOKE]

\section{Socializing (6)}

How often do you do the following ... Spend a social evening with relatives? [SOCREL] Spend a social evening with someone who lives in your neighborhood? [SOCOMMUN] Spend a social evening with friends who live outside the neighborhood? [SOCFREND] Go to a bar or tavern? [SOCBAR] Spend a social evening with your parents? [SOCPARS] Spend a social evening with a brother or sister? [SOCSIBS]

\section{Spouse's Ethnicity (5)}

From what part of the world did your spouse's ancestors come? [SPETHNIC, SPETH1, SPETH2, SPETH3, SPETHNUM]

\section{Spouse's Religion (10)}

What is your spouse's religious preference? [SPREL] If Protestant, what denomination? [SPDEN] If Jewish, Do you consider yourself Orthodox. . . ? [SPJEW] [SPFUND] In what religion was your spouse raised? [SPREL16] If Protestant, what denomination? [SPDEN16] If Jewish, Do you consider yourself Orthodox? [SPJEW16] [SPFUND16]

\section{Suicide (16)}

Within the past 12 months, how many people have you known personally that have committed suicide? [SUIKNEW] Think about the person you knew best that has committed suicide. Describe your relationship to that person. [SUIWHO] Was that person male or female? [SUISEX] How old? [SUIAGE] Race? [SUIRACE] State/region? [SUIREG]

Second closest person: [SUIWHO2, SUISEX2, SUIAGE2, SUIRACE2, SUIREG2]

Third closest person: [SUIWHO3, 
SUISEX3, SUIAGE3, SUIRACE3, SUIREG3]

\section{Tolerance (3)}

Should an admitted Communist be allowed to make a speech in your community? [SPKCOM] Suppose he is teaching in college. Should he be fired or not? [COLCOM] If he wrote a book, would you favor/oppose removing it from the public library? [LIBCOM]

\section{Trauma (12)}

Traumatic events in last five years . . . Divorce? [DIVORCE5] Hospitalization and disability? [HOSDIS5] Death of relatives? [DEATH5] Unemployment?

[UNEMP5]

Number of relatives dying [DEATH16] Death of R.'s father [PADEATH] Death of R.'s mother? [MADEATH] Death of child or child's spouse [CHLDDTH] Death of sibling or sibling-in-law [SIBDEATH] Death of spouse [SPDEATH]

Number of traumatic events in last year [TRAUMA1] Number of traumatic events in last five years [TRAUMA5]
25. Union Membership (1)

Do you or your spouse belong to a labor union? [UNION]

26. Veteran Status (1)

What was your total time on active duty in the military? [VETYEARS]

27. View of People (3)

Would you say that most of the time people try to be helpful, or that they are mostly just looking out for themselves? [HELPFUL] Do you think most people would try to take advantage of you if they got a chance, or would they try to be fair? [FAIR] Generally speaking, would you say that most people can be trusted or that you can't be too careful in dealing with people? [TRUST]

28. Victimizations (6)

During the last year, did anyone break into your home? [BURGLR] Did anyone take something directly from you by force? [ROBBRY] Have you ever been punched or beaten by another person? [HIT] Did this happen to you as a child or as an adult? [HITAGE] Have you ever been threatened with a gun, or shot at? [GUN] Did this happen to you as a child or as an adult? [GUNAGE]

29. Violence (6)

Are there any situations that you can imagine in which you would approve of a man punching an adult male stranger? [HITOK] Would you approve if a stranger . . . Was in a protest march showing opposition to the other man's views? [HITMARCH] Was drunk and bumped into the man and his wife on the street? [HITDRUNK] If the man punched a stranger who had hit the man's child after the child accidentally damaged the stranger's car? [HITCHILD] Was beating up a woman and the man saw it? [HITBEATR] Had broken into the man's house? [HITROBBR]

30. Wiretapping (1)

Everything considered, would you say that, in general, you approve or disapprove of wiretapping? [WIRTAP]

\section{Survey of Journals \\ Report of the Committee on the Status of Women in the Profession}

In 1990, the APSA's Committee on the Status of Women in the Profession (CSWP) requested information about the participation of women on the editorial boards and in the pages of political science journals. The CSWP also sought information about the publication of articles on all aspects of women and politics. This report summarizes the information collected from the survey.*

\section{The Survey}

The editors of 55 political and social science journals were surveyed about the involvement of women as editors and authors, and also about the publication of articles on gender and politics in the journals.

The specific questions in the survey asked for the numbers of women on editorial boards, numbers of articles authored and co-authored by women, and articles addressing gender and politics research submitted and published in six major fields of political science. Information on these topics was sought for each of the last three years.

\section{The Findings}

Thirty journal editors $(55 \%)$ responded to the survey completely or partially. The responses are presented here in terms of the major categories of the survey, along with comparison figures of numbers of women in the profession.

Editorial Boards. The editorial boards of the journals studied averaged 31 members, of whom five were women $-16 \%$. The proportion of women editorial board members varied by only $1 \%$ annually in the three years studied.

The Policy Studies Journal reported the highest proportion of women on the editorial board, $29 \%$. Public Choice reported no women on their board in the past three years. The APSR reported that $15 \%$ of its editorial board members were women.

For comparison, women are $24 \%$ of all faculty in political science, $20 \%$ of faculty at Ph.D.-granting institutions; and $11 \%$ of faculty holding ranks of associate and full professor. Relative to these figures, women are represented on editorial boards at a rate less than their proportion of all faculty, but greater than the proportion of women in advanced ranks.

Authors. Twenty percent of the articles published by the responding journals have at least one woman author: $10 \%$ are single authored by a woman; $1 \%$ are co-authored by women; and $9 \%$ are co-authored by men and women. Women wrote $15 \%$ of all articles published by a single author.

Social Forces had the highest publication rate for women in the survey: $41 \%$ of its articles over the past three years had a woman author 
or co-author. The Journal of Theoretical Politics reported that just 2\% of its articles included a woman author. The APSR had $14 \%$ of its articles over the three-year period written by a woman author or coauthor.

In general, women wrote singly or jointly about one-fifth of all articles in the journals studied. The correlation between the proportion of women on the editorial board and proportion of articles with women as authors or co-authors was .55.

To estimate overall participation by male and female authors, we have assumed that all co-authored articles had just two authors. On this basis, women are estimated to be $16 \%$ of all authors. This is lower than the percentage of all articles that include women as authors since men coauthor with men more often than women co-author with women. In comparison, as noted above, $24 \%$ of all faculty and $11 \%$ of faculty holding advanced ranks are women, bracketing the publication rate by women.

Submissions. The journal editors were asked to classify submissions and published articles by major fields of political science, and by whether articles addressed themes of gender and politics. Many editors said they were unable to do this, and the number of respondents for this question thus was much smaller. Twelve editors answered questions about submission rates, and 18 responded about publication rates.

Aggregating all of the fields, $2 \%$ of articles submitted to the journals were reported to address themes of gender and politics ( 37 of 1,533 submissions). Articles on this theme constituted $4 \%$ of all published articles (28 of 667), suggesting submissions

\section{Women in American Politics}

These monographs, designed for use in undergraduate courses, can be used individually to augment textbooks, or collectively to offer a course on women and politics.

- Women in the Judicial Process, by Beverly B. Cook, Leslie F. Goldstein, Karen O'Connor, and Susette M. Talarico.

- Women's Movements: Organizing for Change, by Joyce Gelb and Ethel Klein.

- Women and Power in American Politics, by Milda K. Hedblom.

- Women, Political Action, and Political Participation, by Virginia Sapiro.

- Women's Rights, Feminism, and Politics in the United States, by Mary Lyndon Shanley with an Introduction and Epilogue by Shelby Lewis.

$\$ 6.50$ each or $\$ 5.00$ for two or more titles. Order from APSA/ Publications. See order form in back of this issue of PS for shipping charges and ordering information.

on gender and politics have a reasonably good acceptance rate.

Among the 12 journals responding fully to these questions, one-fifth of all submissions were published, but one-third of the articles submitted on gender and politics were published. Again, these data suggest a receptivity in these journals to articles on women and politics.

Analysis by field is sketchy since the number of cases is small. We found articles on gender and politics more likely to be submitted in fields of American government and public policy (3\% of all submissions) than other fields. The rate was half as frequent in international relations and comparative politics. However, in each field the ratio of published articles to submissions was greater for papers dealing with gender and politics than for papers addressing other topics.

In sum, articles on gender and politics are a very small proportion of all submissions, but when submitted, such articles are more likely to be published than articles in other fields.

\section{Note}

\footnotetext{
*Members of the 1990 Committee on the Status of Women in the Profession were: Dorothy L. Stetson, Florida Atlantic University; Mara Harrington, Vassar College; Mary Katzenstein, Cornell University; Sue Tolleson Rhinehart, Texas Tech University; and Rosemarie Rogers, Tufts University. Karen

O'Connor, Emory University, 1990 President of the Women's Caucus in Political Science, attended this meeting.

Michael Brintnall and Sheilah Mann of the APSA staff assisted the Committee with the design of the survey, and Michael Brintnall did the analysis. The journals surveyed were selected from those listed in Political Science Journal Information, third edition, 1990, published by APSA.
} 